\title{
Introduction-Key Facts About Domestic Abuse: Lessons from Eight Studies
}

\author{
Lawrence Sherman $^{1} \cdot$ Heather Strang ${ }^{2}$. \\ Denis O'Connor ${ }^{2}$
}

This short summary of the contents of our first special issue on domestic abuse is addressed to everyone who cares about policing this pervasive problem, and especially to the College of Policing (UK) and Chief Constables or Police Commissioners who co-funded the research in each locale. The headline summary of these eight studies is this:

\section{Domestic Homicide}

- Prior attempted suicides or threats are a useful predictor of domestic homicide or attempts (Thornton, Chalkley, Bridger, Button), but new IT systems, data-sharing agreements and analytics are needed to prevent more murders with these facts.

\section{Escalating Seriousness or Frequency?}

- There is virtually no escalation in legal seriousness of reported harm from domestic abuse incidents within the same couples or offenders over time (Barnham, Kerr), except for Australian chronic repeat offenders who are Aboriginal (Kerr).

- The first report of domestic abuse within a couple is usually the last report to police.

- Relatively few repeat, but those who do offend more frequently over time.

Heather Strang

hs404@cam.ac.uk

1 University of Cambridge, University of Maryland, and Cambridge Centre for Evidence-Based Policing, Cambridge, UK

2 University of Cambridge and Cambridge Centre for Evidence-Based Policing, Cambridge, UK 


\section{Preventing Repeat Offending and Harm: Two Randomized Trials}

- Among low-level first offenders, a police requirement to attend a short workshop (on 2 days four weeks apart) can substantially reduce even the predictably low level of harm for a one-year follow-up period (Strang et al.).

- Among a more serious group of repeat offenders, an integrated program of working with both victims and offenders was shown to reduce the harm of repeat offending over a two-year follow-up period (Goosey).

The next section provides more detailed summaries supporting these conclusions.

\section{Separating Fact from Fiction: Eight Pracademic Studies}

Many facts are claimed about domestic abuse, but few are documented by scientific principles of good evidence. The notorious claim that each new case police encounter has been preceded by an average of 35 prior instances of domestic abuse is an example of what claims can be cited as "facts" that do not withstand the test of evidence (Strang et al. 2014). This special issue of the new Cambridge Journal ofEvidence-Based Policing offers eight reports of rigorous efforts to establish key facts about domestic abuse on the basis of good evidence, at least in the agencies where the studies were undertaken.

All eight of these studies were led by serving police officer "pracademics", a concept this Journal defines as "an active practitioner who conducts research meeting high academic standards". All of them were also done under the supervision of a Cambridge University academic as 18,000-word Master's theses for the Cambridge Police Executive Programme and have been shortened by and with the editors for publication in the Journal with necessary and appropriate authorial credit.

Predicting Domestic Homicide The first four articles in this issue examine the capacity to predict domestic homicide in England and Wales. This series of studies was launched by Chief Constable Sara Thornton, currently Chair of the National Police Chiefs' Council, when she returned to Cambridge to complete her Master's thesis while serving as Chief Constable of Thames Valley Police. The subsequent three studies were inspired by her work and constitute replications in various forms using a range of data sets: Inspector Rob Chalkley provides an exact replication in Dorset of Thornton's methods in Thames Valley; Superintendent Eamonn Bridger of Suffolk examines every available post-mortem Domestic Homicide Reviews in England and Wales for two years; Detective Constable Ian Button of Leicestershire Constabulary examines almost 160,000 arrest records to specify the timing of any notice of an offender's suicidal ideation or attempts. Here are the main conclusions about the facts:

- The best available predictor of domestic homicide is offender's prior suicidal behaviour. Compared to a range of other risk factors, domestic murders (both completed and attempted) are most powerfully associated with an offender's history of suicide attempts, threats, ideation, or self-harm.

- Most domestic homicides occur without any prior police contact involving the victim and offender in a relationship. The idea of preventing domestic homicide 
by responding better to domestic abuse is not consistent with the facts: police have very few opportunities to prevent domestic homicide with no prior police contacts unless they can proactively detect couples at high risk through predictors like suicide. Current information systems are inadequate for identifying suicidal behavior among couples with abuse problems known to police. Police have no means at present for instant queries of operational IT as to whether a suspect has a prior history of suicidal ideation. Such queries could be a useful means for identifying dangerous offenders more accurately, and preventing more homicides.

- Organizations other than police hold suicidal behaviour intelligence that could help predict homicide, but do not share it with police. Bridger's analysis of postmortem Domestic Homicide Reviews found that someone had prior knowledge of suicidal behavior by $40 \%$ of men who killed women, but much of that knowledge was never made available to the police until after the death. Legislators may want to reexamine any privacy laws that require this information to be concealed from police and debate the privacy rights of individuals versus the rights of people they may kill.

Tracking Escalation in Seriousness of Abuse Two studies in this issue examine the often-cited "fact" that most cases of domestic abuse escalate in seriousness, especially if repeated over time. Both studies build on Matthew Bland's earlier Cambridge Master's thesis testing that hypothesis in Suffolk (Bland and Ariel 2015). Most findings from these three studies (2 UK and 1 Australian) find that escalation in seriousness is not borne out by the facts in the large samples involved, even with escalation in frequency among a small fraction of cases, with one key exception among a subset of Australian Aboriginals:

- Most cases of intimate partner violence ever reported to police have no subsequent reports to police within a multi-year follow-up period. Both the analysis of over 60,000 cases by former Assistant Commissioner Jeanette Kerr of the Australian Northern Territory Police and Inspector Lee Barnham's analysis of over 50,000 crimes and incidents in Thames Valley confirm Bland's findings from Suffolk: first offence cases are more likely than not to have zero repeat reports, and very low probability of any serious harm subsequent to the initial report.

- Most reported cases of repeat offending drop out after one or more repeat incidents and show no escalation in seriousness.

- Only among the subset of Australian Aboriginals who become chronic cases, with many repeated reports at increasing frequency, is there any evidence of escalation in seriousness of harm. Kerr found that among the Aboriginal Australian offenders in her sample, most did not have much or any repetition of reported incidents with police. Of those who did, however, there was a substantial increase in seriousness of victim harm. This finding provides a unique and important opportunity for investing additional resources for a small subset of victims who are at most risk of serious harm.

- Among offenders who are subjects of three or more domestic abuse cases, an escalation in frequency and probability of future events was found in both Thames Valley and the Australian Northern Territory. Both white and Aboriginal domestic abuse offenders in Northern Territory, as well as all offenders combined in Thames Valley, became more chronic (but not more harmful) with each additional event in a 
standardized time period. The more incidents each offender had, the more likely they were to have another one, and the sooner they were to have it. But not all incidents are created equal. The most serious events can occur on the first offence, or at any time, with no pattern that makes frequency any indication of seriousness.

Testing Reduction of Harm from Domestic Abuse Two studies in this issue test the effectiveness of police-engaged programmes for preventing repeat abuse. One is the multi-year effort of successive Cambridge students from Hampshire Constabulary, a randomized trial of the CARA (Cautioning and Relationship Abuse) Project delivered by the Hampton Trust in Southampton (Strang et al.). The other is a randomized trial of the Bracknell Forest Council's Integrated Case Management programme for couples with at least some repetition of abuse, led by Inspector Jon Goosey. To our knowledge, these are the first two randomized trials of policing domestic abuse conducted in England and the first to show success in reducing harm to victims in repeat offending. This is what they found:

A low-cost conditional cautioning programme for first-offence domestic abusers reduced both harm and frequency of repeat offending (Strang et al.). CARA was randomly assigned to almost 300 eligible offenders with a very high take-up rate. Those offenders assigned to CARA, compared to similar offenders who were cautioned without the requirement to attend CARA, committed substantially lower levels of repeat domestic abuse offending reported to police over a one-year follow-up period, with less legal seriousness of harm and less frequent incidents reported to police.

An integrated case management programme (ICMP) received by couples with repeat violence showed reductions in the harm to victims of reported repeat abuse in the two years after assignment compared to the two years prior, relative to the same before-after comparison among couples not assigned to the ICMP. The sample consisted of 180 eligible couples, half of them randomly assigned to the ICMP group. The experiment was not able to limit social services in the control group as planned, but was very successful in limiting repeated police visits to the home to the ICMP groupand zero visits in the control group. Thus, most of the difference in domestic abuse can be attributed to the only clear difference due to random assignment, the ongoing police visits - not to be confused with the "second responder" approach for which repeated experiments show no reduction in the harm of repeat abuse (Davis et al. 2010).

\section{So What?}

How is the capability of policing to tackle domestic abuse increased by these eight studies? Our conclusions focus on saving lives, reducing harm, and testing what works for making the best choices in managing limited resources.

Saving Lives The possibility of preventing domestic homicide drives a vast array of unfocused and untested police practices. Focusing prediction on good evidence of risk 
associated with suicide is one way out of this problem. Since most cases of domestic abuse never escalate to a homicide, and most domestic homicide cases involve no prior contact with police, the triage for saving lives may be greater investment in proactively detecting hidden risks for better prediction and prevention of high-harm abuse.

Reducing Harm The resources for proactive prevention of murder and serious injury may be found in some re-allocation of the current investment of responses to the high volume of non-injurious cases that are reported to police. The articles in this issue provide strong evidence falsifying the assumption that most reported cases escalate in seriousness, at least as measured by further reports to police. That evidence should give police chiefs greater confidence in considering new approaches for testing resource reallocations for reducing harm.

Testing What Works However police agencies may choose to re-allocate their domestic abuse resource portfolio, the evidence-based model for testing innovations should be clear. There are both ethical and political reasons to introduce domestic abuse strategies with the same care as public health strategies. Both CARA and the Bracknell Forest ICMP were tested with as much rigour as testing a new pharmaceutical. If two English police agencies can do this, we suggest that others can follow their lead.

Whether the facts reported in these eight studies stand up to replication, however, remains to be seen. Thus, the most concrete answer to the question of "so what?" is that every police agency can now replicate these studies - with a clear precedent - to test their conclusions with local data. Once those findings are in hand in each police agency, there is every reason to take action based on these conclusions. The kind of evidencebased innovations this issue reports from Hampshire and Thames Valley provide strong examples of how policing can better reduce harm to victims of domestic abuse.

\section{References}

Bland, M., \& Ariel, B. (2015). Targeting escalation in reported domestic abuse: evidence from 36,000 callouts. International Criminal Justice Review, 25(1), 30-53.

Davis, R. C., Weisburd, D., \& Hamilton, E. E. (2010). Preventing repeat incidents of family violence: a randomized field test of a second responder program. J Exp Criminol, 6(4), 397-418 https:/www. campbellcollaboration.org/news-and-events/news/second-responder-programs-no-effect-on-abuse.html.

Strang, H., Neyroud, P., \& Sherman, L. (2014). Tracking the evidence for a 'mythical number': Do UK domestic abuse victims suffer an average of 35 assaults before someone calls the police? Policing: $A$ Journal of Policy and Practice, 8(2), 222-228. 